Article

\title{
The Foster Family Process to Maintain the Will to Remain in Foster Care-Implications for a Sustainable Programme
}

\author{
Elisete Diogo ${ }^{1,2,3, *(\mathbb{D})}$ and Francisco Branco ${ }^{1}$ (1) \\ 1 Católica Research Centre for Psychological, Family and Social Wellbeing, Universidade Católica Portuguesa, \\ 1649-023 Lisboa, Portugal; fnbranco@fch.lisboa.ucp.pt \\ 2 Polytechnic Institute of Portalegre, 7300-110 Portalegre, Portugal \\ 3 Interdisciplinary Centre of Social Sciences, Universidade Nova de Lisboa (CICS.NOVA.FCSH/UNL), \\ 1099-085 Lisboa, Portugal \\ * Correspondence: elisetediogo@gmail.com
}

Received: 24 August 2020; Accepted: 23 September 2020; Published: 25 September 2020

\begin{abstract}
There were 7032 children in out-of-home care in 2018 in Portugal. Of these, only 2.8\% were in foster care, despite this being the recommended response according to legal regulations. It is critical that more families be encouraged to become foster carers and also that experienced carers stay in the system to create a sustainable programme. How is the will to foster a child maintained? What can we learn from foster families' experiences to improve childcare and the child protection system? The methodology of this study was based on interviews with foster carers. The analysis was inspired by grounded theory. We found three types of foster families, classified according to their will to leave or remain in foster care-unconditional, hesitant, or retired. The results suggest that the key elements for foster carers to remain in the foster care system are (i) their level of satisfaction with how the previous placement concluded, (ii) keeping in touch with the ex-foster child, (iii) the feeling of acknowledgement by all the stakeholders, and (iv) the quality of social services as well as the support of the professional teams.
\end{abstract}

Keywords: foster care; foster family; foster family remain; sustainability; child welfare system; Portugal

\section{Introduction}

This empirical research, based on a qualitative approach, tries to answer the main research questions "How is the carers' will to foster a child maintained?" and "What can we learn from foster families' experiences to improve childcare and the child protection system?". The aim of the study is to give voice to the foster carers in order to understand their foster experience, namely the elements that contribute to their decision to remain in the foster care system and keep fostering children or just leave.

Only by having a deeper understanding of foster carers' experiences will it be possible to tailor the support given and the social, clinical, and financial benefits. In Portugal, studies on foster care are still limited [1,2]. The lack of investment in this child welfare measure is extremely significant. Looking at the last decade [3], the number of children placed in foster care decreased by $70 \%$. The figures have never been so low. In 2018, there were 200 children in foster families out of 7031 in out-of-home care; that's only $2.8 \%$. Excluding kinship care from Portuguese foster care regulations may be one of the explanations for the huge gap between the number of placements in Portugal and other countries. However, it still does not explain the reason why foster care remains residual as a public policy measure after 2008. Political disinvestment by public authorities, as pointed out by Portuguese researchers $[4,5]$, is unquestionable. In addition, the influence of religious charity networks that offer a very significant 
part of residential care can be presented as another potential reason for the resistance to reform the system, but more systematic research is needed to establish a consistent and complete explanation.

However, foster care constitutes an issue on the social agenda, specifically after the changes to the Portuguese child protection law, Lei de Proteção de Crianças e Jovens em Perigo, (no. 142/2015 of 8 September) in 2015. The law highlights foster care as the recommended measure for out-of-home care children mainly up to 6 years old.

The Portuguese legal framework is in line with the national and international recommendations (e.g., Portuguese Republic Constitution—Constituição da República Portuguesa (1976); Convention on the Rights of the Child; Resolution no. 64/142 of the General Assembly of United Nations of 20 December 2010-Guidelines for the Alternative Care of Children; Recommendation 2013/112/EU Investing in children: breaking the cycle of disadvantage, European Commission, 20 February 2013; [1,4,6,7]) on a child's rights to grow up in family-based care; however, the reality of the child protection system remains different. At the end of 2019, a new regulation (Decreto-Lei no. 139/2019, 16 September) was published. This revision of the legal framework highlights the importance of recruiting, training, and supporting families who become carers. Families are recruited, trained, and supported by multidisciplinary teams which work for entities that offer a foster care program in Portugal. To be developed and sustainable, the improvements to the foster care system must include the recruitment of new families who want to become foster carers and also must focus on efforts to keep the experienced carers and learn from their experience as a source to design recruitment and training processes and to evaluate and improve the foster care system.

Sustainability relates to the ability to sustain humanity, civilisations, and the ecosystems on earth. Achieving sustainability is a challenge and one of the most important objectives of a society and its people. Sustainability is a multidimensional concept encompassing economic, social, environmental, and other factors [8]. Therefore, foster care must be thought of and designed in line with the principle of sustainability, as it is a principle of social work [9].

As in other countries, the number of available foster families is insufficient for the system's needs in order to place all the children that would benefit from placement with a foster family. The number of foster families available is a determinant, as noted in the foster care manual Processos-Chave [10], in order to be a sustainable system.

Looking at European countries such as Ireland, England, Spain, or Sweden, and many other countries around the world like Australia, Canada, and the United States of America, foster care is likely to be the preferred placement for children, of course after the biological family if it is not capable of caring for them at that time. The Portuguese scenario is significantly distinct.

With respect to some facts and figures, in Northern Ireland, the empirical data from 2017/2018, revealed that $79 \%$ of children were in foster care [11]. In England, the number is increasing; $73 \%$ of all children looked after were in foster placements in 2018 [12]. In Spain, there were 20,172 children growing up in foster families (which includes children in kinship care) in 2015 [13]. Around the world in Australia, foster care constitutes one of the main interventions of support available to a child [14], according to the Government, $85 \%$ of children living in out-of-home care are in foster care (including kinship care) in 2018. In Canada, 437,283 children are in foster care in 2018, highlighting the increase in children fostered since 1992 when foster care included around 40,000 children [15].

In Portugal, children have always been taken care of by other families in an informal agreement between two families or as an answer to orphans' situations [4]. Four periods define the foster care stages in the Portuguese system: origin, institutionalisation, expansion, and setback. The first stage lasted until the seventies of the twentieth century, and it revealed that foster placements have always existed [4]. According to the facts and figures, foster care in Portugal remains in the setback process. The first law regulating foster care was published in 1979 (DL no. 288/79 of 13 August), but it defined it as a "family placement". Later in 1992 (DL no. 190/92 of 3 September), a new law revealed an effort to improve upon the previous one. In the past, foster care was part of a social benefit instead of a child protection measure as is nowadays. 
The term "foster family" in Portugal denotes a single person or a couple, specifically qualified for the task of placing a child or an adolescent and taking care of him or her, addressing his/her needs, and promoting the child's well-being and education needed for global development (Decreto-Lei no. $139 / 2019$ of 16 September). Since 2008 , foster care kinship has not been allowed. If a caregiver is a relative of the foster child, it is not considered foster care; it is a biological family measure to support the child's family. Since then, the number of children placed in foster care has been decreasing significantly, as stated previously [3].

In terms of geographic presence, in the north of the country, we find more foster carers, and there are some regions without any foster families and therefore without any fostered children. In the north is where one non-governmental organisation has offered a foster care programme for 12 years in accordance with international standards. Across the country, the social security public institute has the responsibility of carrying out foster care; however, at the moment it is almost residual. Government decentralisation is the tendency.

In Porto District, the foster carer's profile has been characterised by Delgado et al. [4] (p. 80). They are aged, with a poor/basic level of education; wives are likely to be domestic workers. In one third of these foster families, both carers are unemployed. Unemployment reveals their complete availability to take care of a child but also their economic fragility and perhaps professional interest. In Portugal, foster care professionalisation is not possible. Fostering is not conceived as a profession but instead it is considered as a voluntary and solidary activity [2].

Since 1992, foster families have been protected by legal rights (DL no. 190/92 of 3 September). However, after a deep discussion involving a public hearing, carers saw their benefits extended (DL no. 139/2019 of 16 September). This means that they receive, after January 2020, a monthly allowance of around $522.91 €$ per child, and a bonus of $15 \%$ for children up to 6 years old or for children with special needs. The law focuses on duties as well.

A foster family is required to give emotional security, affection, and love to a child, but the family must also be available to collaborate in the recovery of the child's family [16], for example, maintaining a cordial relationship and connection, giving a positive/neutral image of the birth family, and promoting child-parents contact. Martins [17] highlights that carers are involved in a complex situation, perhaps with rivalry and antagonism. However, the relationship built between the social actors may lead to different scenarios.

Reasons to foster a child in Porto District are based on affective and humanistic motivations, a love of children and a desire to help [1]. Financial motivation is not significant as findings from a recent research study [2] indicate. The authors also find the transmission of social values to biological children as a motivation to foster. Personal and family life paths can foster the desire to take care of and protect a child who was maltreated in the past. So, in Portugal, in line with other countries, it seems that the motivation to become a foster family stems from one or more of these three drivers: child-centred reasons, self-oriented reasons, and society-oriented reasons, with the focus likely being on the child-centred reason [18]. In Portugal, it seems unlikely to find "second families" among families experiencing the empty nest syndrome, as found by Schofield et al. [19], because one of the family features in southern countries like Portugal is precisely that adult children still live in their parents' home [5].

About the fostering experience, Delgado et al. [4] have found that in Portugal carers appreciate the love given by the foster child and that carers give this love back. Negative aspects are the financial costs and the fear of losing the child. Only one of the participants referred to the child's behaviour and social discrimination. Diogo [5] identifies the experience as rewarding, as well as feeling valued by society, but also with challenges.

Finally, in terms of the will to continue fostering children, retention success is not easily defined and may be different for different types of caring models [20]. Nevertheless, Sinclair et al. [21] state that foster carers must feel supported; therefore, the principles of the kind of fostering that carers are asked to undertake must fit with foster families' situations and preferences. Foster families need to be treated as part of the team and of the support system, and foster carers need a supportive response to 
critical events (such as placement breakdown and abuse allegations). Early intervention might help to prevent this sort of event.

In summary, to invest in new and experienced foster carers seems to be the secure path for the Portuguese government and social services in order to achieve a solid child protection system.

\section{Materials and Methods}

This research and methodology described here is part of an empirical PhD study based on a qualitative approach. It is inspired by grounded theory. We intend that this qualitative tradition, narrative interviews and grounded theory contribute "to reduce [the] possibilities of importing preconceived assumptions such as those about human intentions, actions, and meanings and minimise letting ethnocentric, gender, class, or racial biases seep into the analysis" (p. 181) [22]. The PhD student and her supervisor started conducting research on foster families in Portugal in 2014 during the PhD programme. Since then, they have continued to develop several studies on foster care, including a postdoctoral programme in order to contribute to gathering more extended and robust evidence about this social reality and to contribute to the improvement of public policies in this relevant field.

The paper's main research questions are the following: "How is the will to foster a child maintained?" and "What can we learn from a foster family's experiences to improve the childcare and the child protection system?". These research questions, as a starting point of this study, seek descriptions and understandings [23] of the meanings for carers. The aim of the study is to give voice to the foster carers to understand their foster experience, namely the elements that contribute to their decision to remain in the foster care system and keep fostering children or just leave. By knowing foster carers' experiences, meanings, and decisions more deeply, it will be possible to adjust the given support and the social, clinical, and financial benefits as core dimensions of the sustainability of foster care programmes.

\subsection{Sampling}

The study adopted a theoretical sampling orientation [24], which means that the participants were selected gradually in the field and strategically in compliance with the empirical data, i.e., a data-driven approach was used. We were asking who was the next promising case/foster family according the research questions.

For the selection of participants, in terms of research criteria, maximum variation was followed [24]. The selection decisions were based on a literature review and on an analysis of the foster family case files. Therefore, the sample for this study includes families:

a. With a biological child in their household.

b. With independent biological children.

c. Experiencing their first foster placement.

d. Experiencing their second or subsequent foster placement.

e. With a placement that has ended.

f. Fostering children with disabilities.

g. That have thought about leaving foster care.

The foster families were supported by teams of 3 foster care organisations: (i) Comissão de Proteção de Crianças e Jovens em Perigo (CPCJ), a public commission to protect children; (ii) Segurança Social, a public institute; and (iii) an NGO (the only one). These last two were the only two organisations that offered a foster care programme by the date of the data collection.

In terms of sociodemographic characteristics, the study participants had their own children; indicating previous experience with parenting children. All participants were of Portuguese nationality, and at the time of interview they were, on average, 46 years old. Monthly incomes were in the range of $€ 1000$ to $€ 2000$. All the males worked in a full-time job, but half of the females were not fully employed. In terms of education, they have concluded only primary school. 
Confidentiality was respected. In order to conceal the participants' identification, codes were created such as "FF", meaning "foster family", "ONG", meaning foster carers supported by the NGO team, "SS", meaning foster carers supported by the social security team, "CPCJ", meaning foster carers supported by a team of the commission of child protection (called Comissão de Proteção de Crianças e Jovens em Perigo), and finally "Ex", meaning that a family is no longer a foster family.

\subsection{Data Gathering}

The research design used narrative interviews to gather in-depth information [24] from foster carers. This interview technique begins with a generative question that is designed to stimulate the participant's narrative [24]. This approach was suggested as a research development by Delgado [4], the most notable researcher on foster care in Portugal, who has highlighted the need for more studies on this issue.

Narrative interviews were conducted with 10 foster families. Five interviews were conducted, individually, with the female carer (FFONG1, FFONG2, FFONG3, FFONG4, FFSS1) or, jointly, with the couple (with the others five families: FFONG5, exFFONG, FFSS2, FFSS3, exFFCPCJ). In cases in which the interview was conducted only with one participant, it was the female carer because the male was unavailable (i.e., due to death, or being at work, including some situations working abroad). The researcher suggested that the couple participate, and when that happened, the couple felt good and in harmony for talking about the foster experience together because it had never occurred before with such profundity. Each narrative was about $1.40 \mathrm{~h}$.

The data gathering was carried out between December 2015 and April 2016 in 3 Portuguese districts: Braga, Porto, and Lisbon. The selected districts met the criteria of maximum variation and convenience [24], considering the geographical distribution of foster families in Portugal. There were $130 \mathrm{~h}$ of content recorded.

The empirical part of the study benefitted from the collaboration of the support teams to provide foster families' telephone number and, in some situations, to establish a room for the interviews, especially if a family preferred to conduct the conversation outside the house. Some other interviews were carried out at the house of the participants, so families felt more comfortable participating in the interview because they could have their children with them during the interview and not worry about finding child care if they had to go outside their home in order to participate in the interviews.

Prior to data gathering and conducting interviews, informed consent was sought from the participants. The interviews, each lasting about $1.40 \mathrm{~h}$, were audio recorded. There were $130 \mathrm{~h}$ of content recorded, which were later transcribed by the authors and analyzed.

\subsection{Qualitative Analysis}

The qualitative analysis of the interview data was inspired by grounded theory, following Kathy Charmaz's work [22]. The aim of grounded theory, in the end, is to construct theoretical discoveries rooted on the data from the ground up. Charmaz [22] underlines that we might see in participants' statements aspects to explore further and to learn how the research participants' lives are, as happened in this study with those who have experienced foster care. Moreover, using grounded theory methods allows us to construct an original analysis of the data, as "Grounded theory offers tools to get at varied constructions or competing definitions of the situation" (p. 180) [22] based on an abstract level from the empirical data. As the interviews were transcribed verbatim and anonymised, and participants were assured of confidentiality, then the theoretical coding used the MaxQDA12, a specialised software to conduct a qualitative data analysis. The coding consists of a very deep and abstract process. As Charmaz [22] suggests, it starts very close to the empirical data, doing a line-by-line coding (e.g., quote: "I really want to keep fostering children forever, as long as I can; I don't want to stop it"; line-by-line coding: "expressing her desire to foster a child until it is possible for her"). Following this process, several pages of initial codes were produced. Later, a focused coding was performed. During this coding process, we wrote some memos [22], both initial and advanced. In addition, 
diagrams were used to support the analytical interpretation. The memos and diagrams allow data to be studied by comparing different subcodes, categories/subcategories and interview segments with each other. Finally, the initial developed codes were revised and modified to fit and reflect the participants' responses as more of the interviews were examined and analyzed. At the end, this process led to a new theoretical finding and thus some recommendations for the support teams and for public policies, based on scientific evidence.

Regular meetings and cross-coding discussions between the $\mathrm{PhD}$ student and her supervisor were conducted. This ensured the development of shared perspectives, for example, on coding decisions, theoretical categories saturation, memos, diagram elaboration, and theory construction.

\section{Results}

In terms of the process of building the willingness to keep fostering children, the qualitative data analysis resulted in the identification of three different family groups that we designated as "unconditional foster families", "hesitant foster families", and "retired foster families".

Among the participants, the most experienced foster families were in the first group (which includes three families), "the unconditional FFs", who stated that fostering is "like an addiction" (FFONG3 carer, unemployed, 48 years old), to quote the words of one of this group's carers. This sort of family does not imagine themselves without children around, and they are available to place two or three children at the same time. They wish to foster for as long as possible, until they are unable to do so. These types of "unconditional carers" have extensive foster experience, and it is likely that the female carers are not employed, so it seems that they have dedicated themselves exclusively to the foster task, as being equivalent to a job. Fostering reveals itself to be a positive and rewarding occupation, and the negative aspects involved do not matter. These families show a lot of energy and motivation, and they are encouraged and supported by their friends and relatives. They treat the foster children as though they are really members of the family. These stories reveal that friends and relatives can represent an important resource for the carers' emotional well-being, especially at the end of a placement. These different aspects that drive the carers to renew this desire to continue fostering are expressed in different foster care experience narratives:

“He [foster child] was like a fresh air. My friends said, 'You are not the same person as a week ago'. [ ... ] fostering a child enriches us; it is a remarkable experience. While I can be a foster carer, I will. I do not like to be alone. [ . . ] I feel capable, I have energy to receive more children".

(FFONG1 carer, hairdresser, 51 years old)

“[our relatives] love him [foster child] very much. The 'grandma' is my mother. When the phone rings, [the foster children say] -It is grandma! ( . . ) She has breakfast daily with us. [The foster children say] 'Grandma, come. Grandma, come in!'”.

(FFONG4 carer, domestic servant, 44 years old)

"they [relatives] help us to take care of him [foster child]. At Christmas there is an exchange of gifts; a child there is considered a family member, it is normal. It is a great party with friends and family".

(FFONG3 carer, unemployed, 48 years old)

The second group of families among the participants (which includes five families), called "hesitant foster families", was experiencing their first foster placement (in this group, we can also find the carers who stopped fostering, the ex-FFs). They were facing several challenges that caused some reluctance about staying in or quitting the foster care system. However, carers were conscious of the fact that they were playing an important role for the foster child placed with them. Encouragement and support from the people close to them are fragile. It is likely that the biological children and husband 
express no intention to keep fostering children. However, when asked to reflect on a hypothetical new foster placement, the hesitant families expressed interest. Nevertheless, participants expressed some preferences about possible future placements. Preferences included fostering younger children, justified by the perspective of building a relationship with the foster child more easily, as well as easier child behaviour management, and the intention to place siblings together as support for each other in ludic and emotional contexts.

"-Everybody was against us. Her brother, her sister-in-law, her niece stopped talking with her; Everybody said that it was an absurdity, -You are not fine!".

(exFFONG carer)

"[Imagine fostering another child] It depends; when we say goodbye to her [foster child], how we are going to react [Imagine that you receive a call right now asking you to place a child] It would be possible!"

(FFONG2 carer, school worker, 41 years old)

The third group in this study, the retired foster families (which includes two families), did not want to keep foster children because of their own later stage of life. These types of carers included grandparents, those losing physical and psychological capacities, and those who wanted to dedicate themselves to their own family, their children, and their grandchildren. They were not encouraged to receive more foster children. Feeling that they have already made their own social contribution to children's development, they did not intend to continue fostering.

"No, it is the age, I am 62 years old; She is getting tired; And I have also my grandchildren."

(FFSS2 carers, female, domestic servant, 62 years old and male, retired, 66 years old)

Attempting to construct an integrated interpretation of the dimensions of intervening in the carers' process of maintaining the will to remain in foster care, the findings of the present study offer evidence for several factors. One of these elements is related with the detachment stage. According to the narratives of foster families, the detachment process seems key for carers to either stay in or quit foster care system. Despite being previously prepared, leaving the foster child represents a sad and distressing moment. Consequently, it can lead to sadness, suffering, insomnia, and crying:

"a squeeze in the heart!"

(FFONG1 carer, hairdresser, 51 years old)

"living in a hell ..."

(FFONG3 carer, unemployed, 48 years old)

It is not, however, only the separation from the foster child that plays into the foster family's decision, but also his/her destiny that causes concern and anxiety. In some situations, carers in this research disagreed with the social worker's assessment and held the view that the foster child should not return to his/her family. Several circumstances supported their opinions, such as housing conditions, among others. They felt that the child would not continue to benefit from the adequate care and the development progress experience during the foster family placement. The anxiety is based on the total disruption of the foster family-foster child relationship:

"my biggest fear is to lose touch [with the foster child] definitely"

(FFONG4 carer, domestic servant, 44 years old)

Therefore, there is a sense of satisfaction and relief when the foster family keeps in touch with the foster child after the end of the placement: 
"I am not concerned because he [foster child] left but he calls me on Skype, WhatsApp, Facebook, and his mother too. He arrived in France yesterday because I know he went to France, and he goes to my home."

(FFONG1 carer, hairdresser, 51 years old)

The global impact of the fostering experience influences the decision to keep fostering children. It goes from addressing the initial expectations through to the daily dynamics, the impact of fostering on biological children, and child behaviour management. Unfulfilled expectations and significant changes to daily routines lead to a diminishing motivation to foster. The foster child's behaviour is often the most challenging aspect, warranted by his/her previous life path. When the impact of fostering causes damage to biological children, carers tend to delay or refuse new placements.

"when he arrived home, we had to do a lot ... , he doesn't sleep alone. ( . . ) at the moment the reward is a chocolate from the Christmas calendar. He has more closed days than opened days; however, very good behaviour leads to opening a door."

(FFONG5 carer, family support worker, 42 years old)

"-He [son] is beginning to reject school, to not want to do things that he usually did. I think that it was due to their [foster children] presence; ( . . ) By now, no [keep fostering]. While our son is still young. Maybe, someday. When he changes. It depends on the foster child, she/he is older than him, if she/he does not need so much help, I am sure he [biological son] will accept it."

(exFFONG carer)

Although fostering presents challenges, the experience also has rewarding outcomes in everyday life. The return comes from the stakeholders involved, e.g., the foster child, her/his biological family, the support team, relatives, and friends. It is a reward system fed by different perspectives. Being recognised and loved by the foster child, as well as the child's developmental achievements, seem relevant for carers. The opposite, however, when it occurs, makes the foster carers feel hurt. The compliments from society at large, from across the social network, and from the support team allow carers to feel satisfaction and reinforce the disposition to continue to foster.

"when he [foster child] told me 'I 'd rather you be my mother ... because it makes us feel good', it evidences that he is really good here, he feels good. ( . . . ) his smile is enough!"

(FFONG5 carer, family support worker, 42 years old)

"I was sad [with the foster child], I am still. I don't regret anything, but I am hurt. I never thought that she could tell me 'I am tired of being here' ... there is no reason. We just wanted her to be grown up."

(exFFCPCJ carer, teacher, 38 years old)

"Congratulations, I have known that you are fostering a child. It must be courage."

(FFONG2 carer, school worker, 41 years old)

"They [the social workers] trust me a lot, and they must!"

(FFSS2 carer, domestic servant, 62 years old)

Another relevant driver of the renewal process that seems to be relevant is the carers' role legitimacy, especially with respect to being involved in making decisions about the child's life course, such as decisions on future integration at the end of the foster placement. Words and actions of value must necessarily be complemented by professional support in order for the foster family to feel competent, and to ensure economic and material benefits. The carers should not pay for the foster child's expenses. They already work hard by taking care of them without a salary. 
"-the money given by the Government ... a foster family is poorly paid! They [the foster children] are like our children, we need to take them to the doctor. He [foster child] has a lot of health problems. I take him to the psychiatrist, and I pay the consult. At the first placement [it was different], when I needed to take the children to the doctor, then I sent the receipt to the Social Security and they reimbursed me. Nowadays, I pay all the expenses. Just for the medicines, I spend $85 €$ every month."

(FFSS2 carers, female, domestic servant, 62 years old and male, retired, 66 years old)

Overall, the Figure 1 integrates the dimensions that represent the carers' process of maintaining the will to remain in foster care. It is understood that the impacts of previous foster placements, the reward system, and the management of the detachment process influence the will for a foster family to keep fostering children. The impacts of fostering seem to be centred on the management of the initial expectations, the daily changes, the impact on their own children, and finally the management of the foster child's behaviour. With respect to the reward system related to fostering, we understand that it is filled by (a) the recognition and being valued (from all the stakeholders, including the foster child, his/her biological family, friends, and the support team), (b) the quality of support from public services (emotional and instrumental support level and legitimisation of the carers' role), and (c) the legal framework (legal autonomy, financial and material rewards, and also social status). Finally, the management of the detachment is related to the quality of the previous preparation and support during the child transition process at the end of the placement. It can be painful for both the foster family and the foster child. A good relationship with the biological family may mean keeping in touch with the foster child after his/her return home.

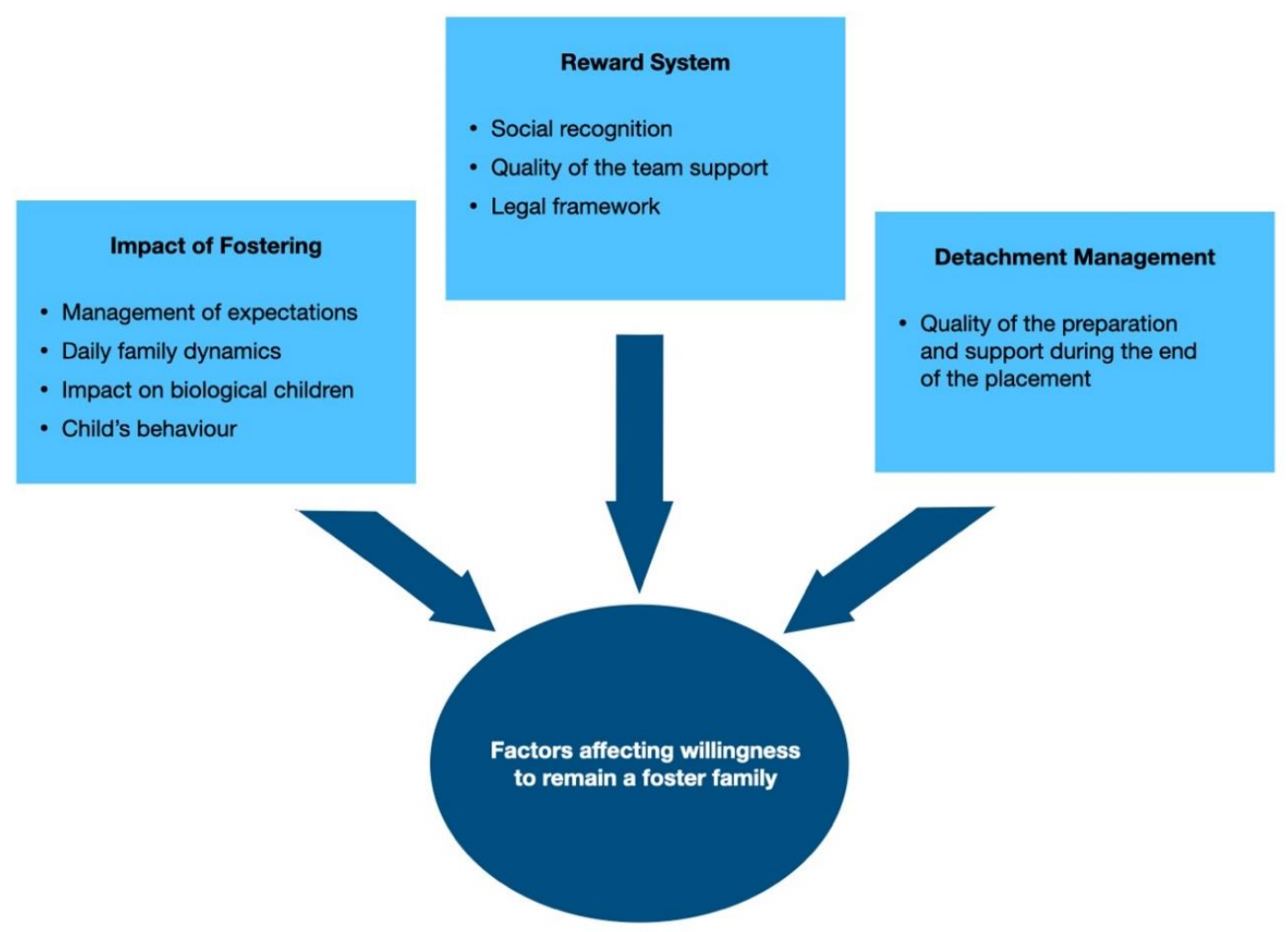

Figure 1. Factors affecting willingness to remain a foster family (own elaboration).

Figure 2 frames the participating carers into three different family groups: "unconditional foster families", "hesitant foster families", and "retired foster families". Foster families with more experience feel that fostering is an addictive task; they cannot imagine themselves without children around, so they are available to place more than one child at the same time and want to be a foster family until 
something prevents them from doing so. Their friends and relatives encourage and support them to continue fostering. Hesitant foster families (and those who have stopped fostering) are in their first placement, experiencing challenges that make their opinion very volatile. The term "retired" can be applied to the families who have chosen not to continue fostering due to their age.
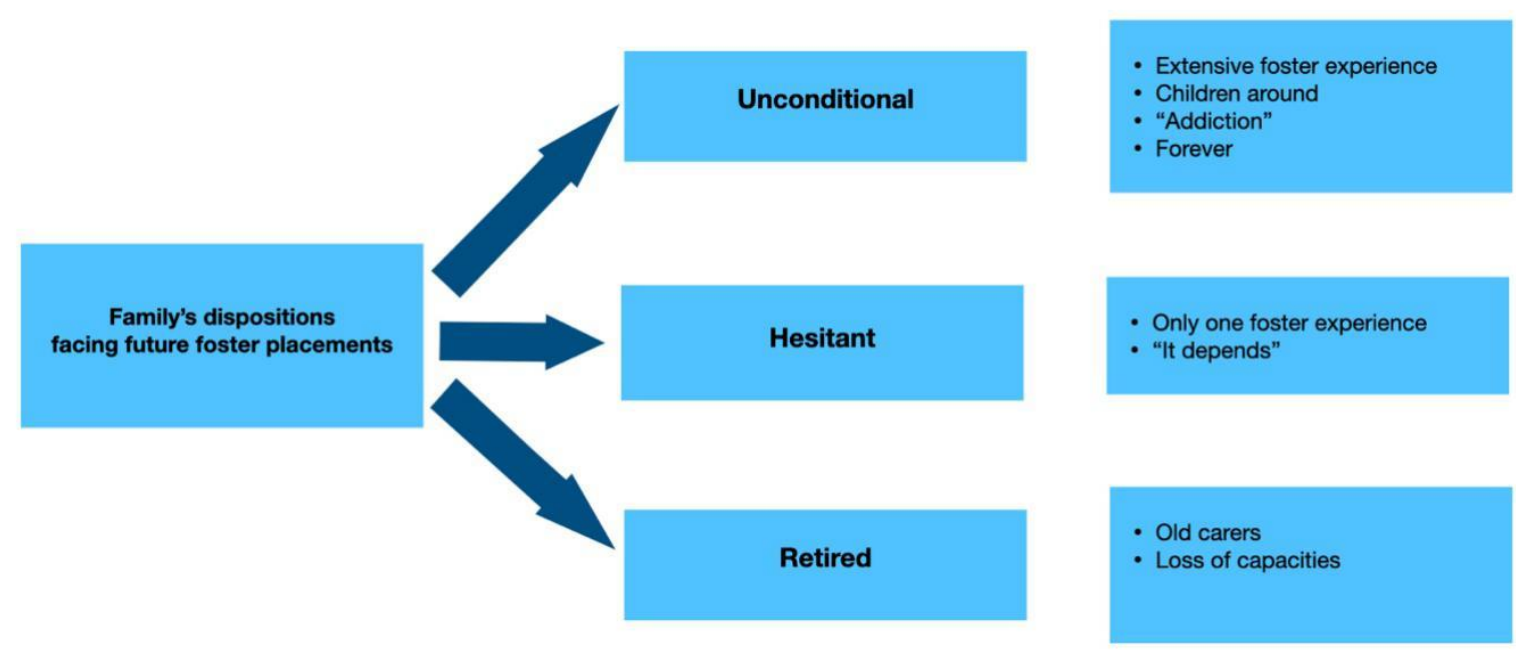

Figure 2. Family's dispositions facing future foster placements (own elaboration).

\section{Discussion}

The present study provides evidence that (i) the impacts of fostering, (ii) the reward system, and (iii) the detachment process influence the will of a foster family to keep fostering children. The impacts of fostering seem to be centred on the management of the initial expectations, the daily changes, the impact on their own children and finally the management of the foster child's behaviour. With respect to the reward system related to fostering, we found that it is filled by (a) the recognition and valorisation (from all the stakeholders, including the foster child, his/her biological family, friends, and the support team), (b) the quality of support from the public services (emotional and instrumental support level and legitimisation of the carers' role), and (c) the legal framework (legal autonomy, financial and material rewards, and also social status). Finally, the management of the detachment is related to the quality of the previous preparation and support during the child transition process at the end of the placement. It can be painful for both the foster family and the foster child. A good relationship with the biological family may mean keeping in touch with the foster child after his/her return home. That is what a foster family may wish for.

The happiness that a child may show, caused by belonging to the foster family and the child's development, represents for these carers a significant reward as recompense for their commitment. Friends and close relatives play an important role in the fulfilment process regarding whether they recognise the carers' social value and encourage them to continue the task. In this study, only one foster family was not supported by either their relatives or friends. Therefore, as this started a conflict between them, they thought about quitting fostering. The respect, support, and being valued by the support team and the public services are also relevant for nurturing confidence in their capabilities and performance. From the opposite perspective, when the support team is not seen as professional and responsive, the carers feel demotivated and useless.

Looking at the findings of this study regarding the will to continue fostering foster children in the future, we frame the carers into three different family groups: "unconditional foster families", "hesitant foster families", and "retired foster families". "Unconditional" families are unreserved about accepting a child at their home. They cannot imagine themselves without children around as they always have been, so they are available to place more than one child at the same time. Being a foster family has been their way of life, they have a solid experience and want to keep being a foster family until it is 
not possible. The second group, "Hesitant" foster families (including those who were not fostering at that time) are those in their first foster experience. Whenever asked about fostering, the answer is dubious and is supported by current challenges. It is likely that the biological children or the husband do not want to keep fostering. The third group, "retired" refers to those families who decided stop fostering justifying by their old age. To take care of their health and own family, namely grandchildren, are the core.

In line with unconditional foster families, Sinclair et al. [21] state in their study that the carers who "stay" are those who have more children placed. They understand that a significant part of the families who "leave" really had no intention to foster. One of the reasons to quit fostering is related to the social circumstances (among others, the age) of the retired foster families.

The findings of this study show that social workers must address the carers' needs in a very careful manner, leading to satisfaction and the desire of keep fostering. In terms of professional support, Sinclair et al. (p. 142) [21] found that continuity is associated with "perceived support from other carers, an income from fostering that was higher than predicted, above average levels of training, and the perceived supportiveness of family placement social workers and other professionals". The connection and familiarity with the carers allows social workers to identify and monitor potential stressful situations [25]. The carers' challenges are based on their competence in managing the foster child's behaviour, and in dealing with a child's reactions, features, and life course. The resilience capability of the family to deal with stressful situations is a significant tool for the family's stability [25]. When stress is still there, families experience a significant period of imbalance, disorganisation, and disruption. There are three processes related to the family's resilience that can help carers face adversity and stress: family cohesion, belief in the systems, and coping strategies [26]. If a family in a moment of crisis is flexible and capable of overcoming the crisis, then it will be happy and have success [27].

In order to improve the success of the measure and the carers' satisfaction, the participants of this study made some contributions to help with facing the daily life difficulties. Society sensibilisation, the reimbursement of foster child expenses, social and tax benefits (e.g., parental leave), a systematic assessment in the field, and closer supervision of the foster child, namely the children supported by Segurança Social Public Institute, should be highlighted. The social workers interviewed unanimously said that there is the need for more support and benefits for carers in order to encourage and motivate them. This highlights that taking care of a child involves a huge expense. Delgado [1] suggests that the payment system should distinguish and reward the commitment, the time used, as well as the carers' skills. The practice in Glasgow, Scotland, where there is a career progression incentive, could be replicated in Portugal. Delgado also refers to a possibility of the freedom to choose the financial framework to keep families in the foster care system and to attract new families to become foster families.

The participants affirmed that carers tend to quit fostering when there is damage to their biological children. This aspect may be mitigated strategically, as some carers in this study already were doing so. The literature [28] suggests the involvement of biological children in the decision to become a foster family, informing them about the task of fostering and about the foster child, identifying protected moments to be only with their children, limiting the information, allowing problems to be discussed, and preparing them for the end of the placement in order to alleviate the impact. Through the experience of the placement of another child, the biological children may develop solidarity, fraternity, and share values, or they may just suffer and revolt, creating conflicts.

In summary, the efforts to increase the number of foster care placements through the recruitment of new families it is not enough. Support, training and carer recognition need to be addressed. Some studies offer implications for practice and policies [29], highlighting that social workers should play a role in enhancing the foster families' satisfaction and the success of the placement. Denby et al. [29] stress the importance of institutions making decisions in a timely manner for both the child's well-being and interest, as well as the relevance of respect for carers' motivations, the clarity of each role, and the carer's involvement as a team member. Denby et al. supports that carers should have easy access to 
their social workers and have relief periods between placements. The more experience a family gets, the more likely continuity is, as revealed in this study with the "unconditional foster families".

Some limitations of the research are stated, namely the dimension of the sample and the small scope of the study subject. However, the study was not intended to be a representative one but instead was intended to reveal the diversity found in the field via a very in-depth analysis.

Future research should include participants from the recent foster care programme offered by Santa Casa da Misericórdia of Lisbon, an NGO, and should interpret the findings according to the new law in order to assess its impact on the will to remain in or to leave foster care.

\section{Conclusions}

This study supports that for a sustainable Portuguese foster care programme, there is the need for special investment in order to retain foster families in the system.

The results suggest that the foster carers' level of satisfaction about the end of the previous placement, keeping in touch with the foster child after the end of the placement, feelings of recognition from all the stakeholders, and the quality of the social services as well as the team support are key elements for families to remain in the foster care system.

It seems easy to retain the so-called unconditional foster carers; however, the hesitant foster carers must have more support, or the risk of them leaving the system is very real.

The findings have implications for foster care systems around the world, as they are in line with similar studies.

In addition, the social representation of foster care measures should correspond clearly to the reality. It can happen with a campaign on TV programmes, positive outcomes highlighted in the newspapers, and so on, leading to greater satisfaction and acknowledgement of the carers, thereby improving their daily motivation to continue fostering.

Author Contributions: Conceptualisation, data gathering, analysis, and writing-original draft preparation: E.D. Writing, review and editing, and supervision: F.B. All authors have read and agreed to the published version of the manuscript.

Funding: This research received no external funding.

Conflicts of Interest: The authors declare no conflict of interest.

\section{References}

1. Delgado, P. Acolhimento Familiar-Conceitos, Práticas e (in) Definições; Profedições, Lda: Porto, Portugal, 2007.

2. Diogo, E.; Branco, F. Being a Foster Family in Portugal-Motivations and Experiences. Societies 2017, 7, 37. [CrossRef]

3. Instituto da Segurança Social, I.P. CASA 2018 - Caracterização Anual Da Situação de Acolhimento Das Crianças e Jovens; Instituto da Segurança Social, I.P.: Lisboa, Portugal, 2019.

4. Delgado, P. Acolhimento Familiar de Crianças, Evidências Do Presente, Desafios Para o Futuro; Mais Leituras Editora: Porto, Portugal, 2013.

5. Diogo, E. Ser Família de Acolhimento de Crianças; Universidade Católica Editora: Lisbon, Portugal, 2018.

6. Carvalho, M.J. Sistema Nacional de Acolhimento de Crianças e Jovens, 1st ed.; Fundação Calouste Gulbenkian: Lisbon, Portugal, 2013.

7. Schofield, G.; Beek, M. Providing a Secure Base: Parenting Children in Long-Term Foster Family Care. Attach. Hum. Dev. 2005, 7, 3-25. [CrossRef]

8. Rosen, M.A. Issues, Concepts and Applications for Sustainability. J. Cult. 2018, 3. [CrossRef]

9. International Federation of Social Work. Global Social Work Statement of Ethical Principles. Available online: https://www.ifsw.org/global-social-work-statement-of-ethical-principles/ (accessed on 17 August 2020).

10. Instituto da Segurança Social, I.P. Manual de Processos-Chave-Acolhimento Familiar; Instituto da Segurança Social, I.P.: Lisboa, Portugal, 2009.

11. Department of Health. Children's Social Care Statistics for Northern Ireland 2017/18; Department of Health: New York, NY, USA, 2018. 
12. Department for Education. Children Looked after in England (Including Adoption); Department for Education: London, UK, 2018.

13. Ministerio De Sanidad e Servicios Sociales e Igualdad. Boletín de Datos Estadísticos de Medidas de Protección a La Infancia; Ministerio De Sanidad e Servicios Sociales e Igualdad: Madrid, Spain, 2017.

14. Octoman, O.; McLean, S. Challenging Behaviour in Foster Care: What Supports Do Foster Carers Want? Adopt. Foster. 2014, 38, 149-158. [CrossRef]

15. Doucet, M.; Marion, É.; Trocmé, N. Group Home and Residential Treatment Placements in Child Welfare: Analyzing the 2008 Canadian Incidence Study of Reported Child Abuse and Neglect. 2018. Available online: https://cwrp.ca/publications/group-home-and-residential-treatment-placements-childwelfare-analyzing-2008-canadian (accessed on 24 September 2020).

16. Delgado, P. O Contacto No Acolhimento Familiar-O Que Pensam as Crianças, as Famílias e Os Profissionais; Mais Leituras Editora: Porto, Portugal, 2016.

17. Martins, P. Proteção de Crianças e Jovens Em Itinerários de Risco, Representações Sociais, Modos e Espaços; Instituto de Estudos da Criança da Universidade do Minho: Braga, Portugal, 2004.

18. Rhodes, K. Foster Parents' Reasons for Fostering and Foster Family Utilization. J. Soc. Soc. Welf. 2006, 33, 105.

19. Schofield, G.; Beek, M. Growing Up in Foster Care; British Agencies for Adoption and Fostering: London, UK, 2000.

20. Thomson, L.; Watt, E.; McArthur, M. Literature Review: Foster Carer Attraction, Recruitment, Support and Retention; Institute of Child Protection Studies, Australian Catholic University: Canberra, Australia, 2016.

21. Sinclair, I.; Gibbs, I.; Wilson, K. Foster Carers: Why They Stay and Why They Leave; Jessica Kingsley Publishers: London, UK, 2004.

22. Charmaz, K. Constructing Grounded Theory A Practical Guide Through Qualitative Analysis; SAGE Publications: London, UK, 2006.

23. Blaikie, N. Designing Social Research, 2nd ed.; Polity: Cambridge, UK, 2016.

24. Flick, U. Métodos Qualitativos Na Investigação Cientifica; Monitor-Projetos e Edições: Lisboa, Portugal, 2005.

25. Duis, S.S.; Summers, M.; Summers, C.R. Parent Versus Child Stress in Diverse Family Types: An Ecological Approach. Top. Early Child. Spec. Educ. 1997, 17, 53-73. [CrossRef]

26. Kalil, A. Family Resilience and Good Child Outcomes A Review of the Literature. 2003. Available online: https://www.semanticscholar.org/paper/Family-Resilience-and-Good-Child-Outcomes-A-Review-Kalil/ 41ed83ff82b6d93b2509581374f6e3fcd03b7ecb?p2df (accessed on 25 September 2020).

27. Relvas, A.P. O Ciclo Vital Da Familia_Perspectiva Sistémica; Edições Afrontamento: Porto, Portugal, 1996.

28. Hojer, I.; Sebba, J.; Luke, N. The Impact of Fostering on Foster Carers' Children; Rees Centre, University of Oxford: Oxford, UK, 2013; Volume 26. [CrossRef]

29. Denby, R. Predictors of Foster Parents' Satisfaction and Intent to Continue to foster. Child. Abuse Neglect. 2015, 23, 287-303. [CrossRef]

(C) 2020 by the authors. Licensee MDPI, Basel, Switzerland. This article is an open access article distributed under the terms and conditions of the Creative Commons Attribution (CC BY) license (http://creativecommons.org/licenses/by/4.0/). 